\title{
Hepatitis A: The Costs and Benefits of the Disease Prevention by Vaccine, Paraná, Brazil
}

\author{
Mariana Ribas Zahdi ${ }^{1}$, Ivan Maluf Junior ${ }^{1}$ and Eliane Mara Cesário Pereira Maluf ${ }^{2}$ \\ ${ }^{1}$ Student of Medical Course, Universidade Positivo; ${ }^{2}$ PhD, Professor of Medical Course, Universidade Positivo, Federal University of Paraná; \\ Curitiba, PR, Brazil
}

\begin{abstract}
This study evaluated the epidemiological behavior of the hepatitis $\mathrm{A}$ in Paraná state and compared the costs of the disease and the vaccination. This is an epidemiological descriptive study including a pharmacoeconomy analysis. We collected information in the national database reported cases (SINAN), in the mortality information system (SIM) and in the hospital information system (AIH) among 2000/2003 (Paraná State Public Health Department). We estimated the probability of one cohort of children to acquire hepatitis A during their lifetime and the costs with their treatment. We compared those costs with the cost of vaccinating the children. 14,682 hepatitis A cases were registered during the period studied, and 12,102 (82.4\%) occurred in the 0-15 years-old age group. The annual incidence in the general population was 37.5/100,000. We observed 20 deaths caused by this disease; 7 of those occurred by liver failure. The estimated costs with the disease included the hospital costs, liver transplantation, liver failure treatment, and laboratory tests were high. The price of the vaccine is $10 \mathrm{USD} /$ dose. Two doses are necessary to get the protection. The results showed a positive cost - benefit relation when we vaccinate children. We save 2.26 USD in treatment for each dollar invested in the vaccine. Paraná record high number of hepatitis A cases each year. We confirmed the positive cost benefit relation when we vaccinate children against hepatitis A, reducing suffering, hospitalization, death and social costs. Vaccination against hepatitis A should be recommended in the routine of immunization program in Paraná state. Key-Words: Hepatitis A, vaccine, epidemiology, cost-benefit.
\end{abstract}

Hepatitis A is a disease caused by a RNAvirus that is classified as a member of the picornavirus family [1-3].It is considered an acute benign disease, rarely fatal, normally limited to liver. The lethality, which increases with age, has been reported to be around $0.30 \%$; however it increases to $2 \%$ in patients over 40 years of age [2]. Its clinical manifestation is marked by a self-limited, acute clinical state associated to fever, fatigue, abdominal discomfort, jaundice, anorexia and nausea [4].

Around $70 \%$ of the children, aged 6 years or less, present asymptomatic form of the infection. Older children and adults usually suffer from a symptomatic form of the infection, which can last for a few weeks. Jaundice occurs in $70 \%$ of all cases [2]. Severe cases, such as fulminant hepatitis, are rare. There is no chronic infection [4]. Adults may develop complications such as: cholestasis, arthritis and vasculitis, auto immune hepatitis, acute liver failure, purpura and aplastic anemia [5].The incubation period is around 28 days and represents the period of highest infectiousness [2].Since there is no specific treatment for it, the adoption of preventive measures against hepatitis A is crucial. In order to help with the prevention of the disease, it is important to be aware of how the disease is transmitted. The virus is usually transmitted from person to person or through contaminated food such as raw seafood, or contaminated water. This condition is common in developing countries. In developed regions, the disease is transmitted through sexual contact, especially amongst active

Received on 15 March 2009; revised 12 July 2009.

Address for correspondence: Dr. Eliane Mara Cesário Pereira Maluf. Av. Silva Jardim, 2833, ap. 501, Água Verde, Curitiba - PR. Zip code: 80240-020. E-mail: eliane.cesario@yahoo.com.br.

The Brazilian Journal of Infectious Diseases 2009;13(4):257-261. (C) 2009 by The Brazilian Journal of Infectious Diseases and Contexto Publishing. All rights reserved. homosexuals, and the use of illegal injectable drugs (the most common form of infection in developed countries, in addition to traveling to regions where the disease is endemic) [6-9] and blood transfusions [10]. As a general measure, the implementation of a basic sanitary program should be one of the main actions. Passive immunoprophylaxis, using immunoglobulin intramuscularly, can also be indicated. The immunoglobulin can be used up to two weeks after the initial exposure to the virus. However during a study carried out in Amsterdam in which immunoglobulin was administered to the closed contacts of 596 hepatitis A patients, this measure proved to be ineffective in the prevention of the disease although it had reduced the symptoms [8]. The most effective way to avoid the disease nowadays is with the vaccination. Vaccines against hepatitis A are prepared from the culture of adapted HAV (hepatitis A virus) cells, which are propagated in human fibroblasts, purified by cellular lyses, inactivated by formaldehyde and adsorbed on aluminum hydroxide. Currently available vaccines are recommended for use in individuals over 12 months of age. The effectiveness is reduced in individuals younger than 12 months due to the interference of maternal antibodies. Different formulations for adults and children are available. The administration of two doses, intramuscularly, is recommended. The seroconversion is fast, approximately 12 days (the incubation of the hepatitis A virus lasts around 28 days), so the vaccine can be administered after a short period of exposure to the virus [11]. Adults aged between 20 and 39 years have the fastest rate of seroconversion [12]. The age of vaccination also influences the seroconversion rate. In a study carried out with Thai children who were vaccinated at eight months, $94 \%$ exhibited seroconversion while of those vaccinated at 12 months, 99\% displayed seroconversion [13]. Chinese studies have shown that the immunity induced by the vaccine offers long term (25 years) protection [14]. 
Some pain, redness or edema may occur in the vaccine application site in around 20 to $50 \%$ of the vaccinated people [14]. In the United Kingdom, out of a total of 1 million vaccinated people, 548 reported suffering from mild symptoms such as fatigue, fever and localized cutaneous rash. In the USA, 428 out of 6 million vaccinated individuals reported mild adverse effects [12].

The data regarding the disease are a source of concern:

- There are 1.5 million cases of hepatitis A in the world

- The annual cost for the treatment of the disease is 480 million dollars in the USA.

- Hepatitis A is responsible for 10 to $20 \%$ of all liver failure cases in the United Kingdom.

- Hepatitis A is responsible for $20 \%$ of all liver transplants in Argentina [12].

The Brazilian population is at a high risk of contracting the disease due to the deficient or total lack of sanitary systems in some of the regions of the country. The prevalence in Brazil, determined by serological tests is 65\% [3]. More specifically, in a study carried out in the State of Rio de Janeiro in children at age $10,50 \%$ of the poor class had HAV antibodies while $28 \%$ of middle and higher class [10].In Fortaleza, Ceara more than $90 \%$ of the poor children were infected while less than $25 \%$ in other classes were infected [6]. In Porto Alegre, Rio Grande do Sul, 20\% of the poor children were infected while $3 \%$ in other classes were infected [15].

This study evaluated the epidemiological behavior of Hepatitis A in the State of Paraná, Brazil; and compared the costs of the disease and the costs of active immunization against hepatitis $\mathrm{A}$.

\section{Materials and Methods}

This is an epidemiological descriptive study including a pharmacoeconomy analysis. The development of the project was approved and had support from the Paraná State Health Department (SESA).

\section{Data Collection}

The data collection included:

- AIHs (Authorization for Hospitalization) in the State of Paraná during the period from 2000 to 2003.

- $\quad$ SINAN (National Database of Reported Cases), 2000 to 2003. In the state of Paraná the hepatitis A notification of is compulsory since 1972.

- SIM (Mortality Information System), Paraná, from 2000 to 2003.

- Estimated costs: costs for laboratory tests, treatment of fulminant hepatitis cases, liver transplantation, doctor's visit and the vaccine against hepatitis A were considered. It was based in Brazilian Public Health System of payment for medical procedures.

- Logistic and personnel: two medical students were trained to collect the data. They were supervised by the research coordinator and advised by the State Health Department.
The SPSS statistical program, version 10, was used in the analysis of the data.

The pharmacoeconomy analysis was done with the assistance of an expert on the issue, who is the coordinator of the Infectology Department of the Liver Transplant project in the Dr.Cosme Agerichv Hospital, Buenos Aires, Argentina.

\section{Results}

The Magnitude of Hepatitis A Problem in the State of Paraná Hospital Admission

The analysis of the AIHs data showed that 432 people were hospitalized with hepatitis A diagnosis (CID - International Diseases Classification - B15) with laboratory confirmation. Because the clinical characteristics are similar for all types of acute viral hepatitis, hepatitis A diagnosis was confirmed by a positive serologic test for immunoglobulin M (IgM) antibody to hepatitis A virus (ELISA test).

\section{Hepatitis A Data Reported to the Epidemiological} Surveillance System

The total number of hepatitis A(CID B15) cases registered during the period studied was 14,682.

Table 1 shows the number of cases per year. There was a reduction in the number of reported cases in the last few years.

A higher proportion of hepatitis A cases was observed among males (52.5\%). An increase in the number of reported cases during the months of March, April and May was observed too.

The proportional distribution by region showed the highest number of cases in Curitiba and metropolitan region (30.4\%). This region represents the biggest population concentration of the state.

The age of the patients ranged from 6 months to 89 years, with an average age of 10.1 years. The annual incidence rate of hepatitis A in the State of Paraná was 37.5/100,000 inhabitants/year. Eighty two per cent of the patients were aged 15 years or less.

The hepatitis A incidence rate among those aged 5 years or less was 122.5 cases per 100,000 inhabitants/year. For those aged between 5 and 15, the incidence of cases was 100.3/ $1,000,000$ inhabitants/year. In the 16 to 49 age group, the incidence was 1.9 and for those aged 50 or older 2.31/100,000 inhabitants/year.

Table 1. Distribution of reported hepatitis A cases in the SINAN per year of occurrence, Paraná (2000 to 2003).

\begin{tabular}{lcc}
\hline Year & N cases & \% \\
\hline 2000 & 5,620 & 38.3 \\
2001 & 4,761 & 32.4 \\
2002 & 2,472 & 16.8 \\
2003 & 1,829 & 12.5 \\
Total & 14,682 & 100.0 \\
\hline
\end{tabular}

Font: Paraná Public Health Department. 


\section{Hepatitis A Deaths}

Twenty death certificates were recorded indicating hepatitis A as cause of death. Out of the total number of deaths, 12 (60\%) were female; $50 \%$ of all deaths occurred in those aged 15 or less. The main cause of death was fulminant hepatitis with liver failure which represented $35 \%$ of all deaths.

\section{Estimated Costs}

\section{Cost of the Disease}

In order to assess the cost of the disease, a hypothetical model that shows the probability of a cohort of children, from birth until 50 years of age, acquiring the disease, was created. The costs of the disease were estimated based on the results of the model.

According to the Table 2, there are 177,635 children aged 1 or less in Paraná.

The preparation of a statistical model was based on the data regarding of the incidence of hepatitis A up to 59 years of age (study carried out in Sao Paulo, Roberto Focaccia, et al, 1998, published at the BJID) [16]. Seroprevalence of Hepatitis A antibody is more representative of the population infection rate than the formal register of cases. As there was not a seroprevalence study of Hepatitis A in Paraná State, we chose the data of Sao Paulo research study [17] (Table 3). Example: in the 10 to 14 years age group, $35.81 \%$ are serologically positive (out of an age group population of 13,713 in Paraná). Out of these, $70 \%$ are symptomatic $(9,599)$.

\section{Strategy 1: Do Not Vaccinate}

Variables Reviewed

1) Number of cases: 98,339 .

2) Number of doctor's visit (4 per patient) [17,18]: 393,356 visits.

3) Laboratory tests (blood count, TGP - TGO, bilirubins total and fractions, coagulogram) - three times during the disease [19]: 1,475,085 tests.

4) $\operatorname{IgM}=98,339$ tests.

5) Number of relapses (10\%) [20]: 9,833 cases.

6) Laboratory tests in relapse cases (10\%) - 147,495 tests.

7) Fulminant hepatitis (one for every one thousand symptomatic cases) [21]: 98 cases.

8) Number of liver transplants (80\% of all cases of fulminant hepatitis) [21]: 78 cases.

9) Number of retransplants (20\%) [22]: 15 cases.

\section{Cost (Dollars)}

1) Doctor's visit (1.6 USD/ visit) = 629,369 USD.

2) Laboratory tests (blood count, TGP - TGO, coagulogram, bilirubin) $=$ average of 3.18 USD per test, equals to 4,690,770 USD.

3) Doctor's visit in relapse cases (39,332 cases per 1.6 USD) $=62,931$ USD.

4) Laboratory tests in relapse cases: $(147,495$ tests $)=469,034$ USD.
Table 2. Distribution of the population of Paraná per age group

\begin{tabular}{lr}
\hline Age & Total \\
\hline$<1$ year & 177,635 \\
1 to 4 years old & 732,001 \\
5 to 9 years old & 947,363 \\
10 to 14 years old & 958,834 \\
15 to 19 years old & 972,799 \\
20 to 29 years old & $1,711,221$ \\
30 to 39 years old & $1,549,833$ \\
40 to 49 years old & $1,164,898$ \\
50 years old or over & $1,583,381$ \\
Total & $9,797,965$ \\
* The year 2002 was used since it is an intermediate \\
year, between the years researched in the SINAN. Source: \\
DATASUS/MS.
\end{tabular}

5) IgM for diagnosis $=98,339$ tests (6.16 USD each one) $=$ 599,867 USD.

6) Fulminant hepatitis: 98 cases (each admission to hospital 120 USD) $=11,760$ USD.

7) Number of transplants: 78 cases (each transplant= 17,299 USD) $=1,349,322$ USD.

8) Number de retransplants (17,557 USD per case $)=263,355$ USD.

9) Total: 8,076,408 USD.

\section{Strategy 2: Vaccinate}

Vaccination Cost of a Cohort of 177,635 Live Births

1) Vaccine cost: 10 USD.

2) Two vaccine doses per child: total $=355,270$ USD.

3) Cost of the total vaccine doses $=3,552,700$ USD.

4) Doctor's visit due to adverse events (3\% of those vaccinated $)=10,658$ visits $=17,052$ USD.

5) Total vaccine cost: $3,569,752$ USD

For each US\$1.00 invested in vaccination, US\$ 2.26 is saved from being spent on the disease. Costs related to post exposure prophylaxis, post transplant medications, social problems and hepatitis A death were not included.

\section{Discussion}

According to our data collection, the distribution of HAV cases in Paraná (2000-2003) has shown that $82.4 \%$ of those infected are aged between 0 and 15 years. In Holland, 2004, it was observed the average age of those infected is 35 years, with $77.8 \%$ of them being aged 15 or over [8]. In Paraná, children among $0-15$ years of age correspond of $50 \%$ of all deaths. Probably the pattern is different because they are of different regions. When analyzing the data, it is important to take into consideration the fact that the most serious form of the disease is much more common in adults than in children. In general, literature reports one death for every thousand cases of hepatitis A. However, according to our data, there were 14,682 reported cases and 20 deaths. According to this, the expected result would be 14 deaths. This difference in the number of expected deaths and observed deaths implies that not all cases 
Table 3. Study carried out in Sao Paulo, Roberto Focaccia, et al. 1998 [16].

\begin{tabular}{lccc}
\hline Age Group & \% sorol + $\mathbf{p} /$ hep A & Probable N of infections & N of symptomatic cases* \\
\hline 2 to 4 years old & 12.10 & 21,493 & 6,447 \\
5 to 9 years old & 28.09 & 28,403 & 14,201 \\
10 to 14 years old & 35.81 & 13,713 & 9,599 \\
15 to 17 years old & 56.16 & 36,145 & 25,301 \\
18 to 29 years old & 65.30 & 16,235 & 11,364 \\
30 to 39 years old & 85.89 & 36,415 & 25,490 \\
40 to 49 years old & 90.81 & 8,739 & 6,117 \\
Total number of expected cases of hepatitis (birth until 50 years) & 98,339 \\
\hline
\end{tabular}

are being reported. It is important to consider the lack of etiologic confirmation and some inconsistencies of the reported data in the past $[3,17]$. According to SIM (mortality Information system), liver failure is the main cause of death (35\%) among hepatitis A patients in Paraná. These results are according to the majority of articles published. Our study has shown that children younger than 15 are at most risk of being exposed to the hepatitis A virus. Vaccination should be recommended to children aged 12 months or over. For children younger than 12 months, the seroconversion is impaired due to the presence of maternal antibodies in their system [12].

There are 177,635 children younger than 12 months in Paraná. We developed a hypothetical vaccination strategy for this population group, looking at medium and long term results to eliminate hepatitis A from our State. Based on the cost analysis of vaccination (US\$10 per dose), we would spend to vaccinate all those children US\$3,552,700; adding to this figure a 3\% rate of adverse events caused by the vaccine that require monitoring, our total calculated cost was US\$3,569,752.

The literature confirms the positive cost - benefit relation of Hepatitis A vaccination in a region with a high incidence of this disease. On the other hand, a pharmacoeconomy study about a group of vaccinated children who were from an Amsterdam ethnic minority group didn't show any economical advantage with the vaccination [8]. In Thailand, a similar study was performed with adolescents and it didn't show economical advantage with the vaccination either [13].

Hepatitis A has a high incidence in Chile and it is considered a public health problem there. In that country the vaccination of the population would save around 4 billions of dollars [23]. In the USA, Jacobs RJ et al. studied vaccinated children who lived in a high endemic region and they showed a positive cost - benefit relation of the vaccine [24]. Nowadays Hepatitis A vaccine is recommended in USA and Israel $[25,26]$. Rosenthal P. [27] reviewed some economical analysis about Hepatitis A vaccine and he concluded that its economical benefit is similar the other vaccines that are included in the routine child immunization program. Besides this, it is economically acceptable for adolescents and adults who have a high risk to get this disease.

When analyzing the hepatitis A cases in patients aged 50 or less, taking into accounts the treatment costs, our total cost was US\$ 8,076,408. So, from a financial standpoint, vaccination is definitely advantageous. Prophylaxis of viral infection, besides preventing social issues, avoids deaths and prevents epidemics. Our study did not evaluate the benefit of "herd immunity", but Wasley et al. [28] and Dagan R et al. (2005) [26] showed in United States and Israel studies that a decline in hepatitis A infection rates in children occurred with the vaccination of one group and helped reduce the transmission in other groups, supporting the hypothesis of a strong herd immunity effect.

The incidence of hepatitis A would not be reduced by the vaccination of specific groups in Brazil. The ideal way would be to adopt routine vaccination in children older than 12 months [26].

\section{Conclusion}

Paraná is a region with a high incidence of hepatitis A. Results has confirmed the positive cost-benefit ratio of the vaccination: it avoids suffering, hospital admissions and death, besides reducing social cost. The vaccine is the only alternative to solve the problem in a short period of time. Vaccination against hepatitis A should be recommended in the routine of immunization program in Paraná state.

\section{Recommendations}

In addition to implementing routine vaccination against hepatitis A, the Health Information Systems should be reinforced in order to reduce the number of unreported cases of the disease.

\section{Acknowledgments}

We would like to thank the CIDS (Center of Health Diagnosis and Information) team - Paraná State Health Department.

\section{References}

1. De Paula VS, Baptista ML, Lampe E, Niel C, Gaspar AM. Characterization of hepatitis A virus isolates from subgenotypes IA and IB in Rio de Janeiro, Brazil. J Med Virol 2002; 66: 22 - 27.

2. Valenzuela MTB. Vacunas anti hepatitis A: Estado del arte. Rev Chil Infect 1999; 16 (Supl. 1): 37 - 44.

3. Ministério da Saúde - Brasil. Guia de Vigilância Epidemiológica. $4^{\text {th }}$ ed, 1998; 5-14.

4. Committee on Infectious Diseases, American Academy of Pediatrics. Hepatitis A. 26 $6^{\text {th }}$ ed. Red Book 2003. Ed. Publicações Científicas Ltda. p 355-363. 
5. Almeida LM, Werneck GL, Cairncross S, Coeli CM, Costa MC, Coletty PE. The intensity of transmission of hepatitis A and heterogeneities in socio-environmental, risk factors in Rio de Janeiro, Brazil. Transactions of the Royal Society of Tropical Medicine and Hygiene 2002; 96: 605 - 610.

6. Guimaraens MA, Codeço CT. Experiments with mathematical models to simulate hepatitis A population dynamics under different levels of endemicity. Cad Saúde Pública 2005 Sep Oct; 21 (5): $1531-9$.

7. Lagos RZ, Potin M, Munoz A, Abrego P, San Martin OS, Ureta $\mathrm{AM}$, et al. Anticuerpos séricos contra el virus hepatitis A en sujetos de nivel socioeconómico medio y bajo, en comunas urbanas de Santiago. Rev Méd Chile 1999; 127: 429 - 436.

8. Sonder GJB, Van Steenbergen JE, Bovee LP, Peerbooms PG, Coutinho RA, Van DEN Hoek A. Hepatitis A virus immunity and seroconversion among contacts of acute hepatitis A patients in Amsterdam, 1996 - 2000: An evaluation of current prevention policy. Am J Public Health 2004; 94: 1620 - 1626.

9. Proll S, Nothdurft HD. The risks of contracting hepatitis A or hepatitis B run by visitors to the Mediterranean and Eastern Europe. MMW Fortschr Med 2004; 146 (20): 51 - 54.

10. Medronho RA, Ribeiro SV, Valencia LIO, Fortes BPMD, Braga RCC. Análise espacial da soroprevalência da hepatite A em crianças de uma região carente de Duque de Caxias, RJ, Brasil. Rev Bras Epidemiol 2003; 6:328-34.

11. Gendrel D. Hepatitis A vaccination in children. Med Trop (Mars) 2004; 64 (4): 394-400.

12. Andre F, Van Damme P, Safary A, Banatvala J. Inactivated hepatitis A vaccine: immunogenicity, efficacy, safety and review of official recommendations for use. Expert Rev Vaccines 2002; 1 (1), 9 - 23.

13. Soogarun S, Wiwanitkit V. Vaccinating Thai adolescents against hepatitis A: is it cost- effective? Southeast Asian J Trop Med Public Health, 2002; 33 Suppl 3:145 - 8.

14. Yang CY, Lu CY, Lee CY, Shao PL, Wang CY, Wu TZ, et al. An open study of inactivated hepatitis A vaccine (VAQTA) in Taiwanese healthy adult volunteers: safety, tolerability, and immunogenicity. Microbiol Immunol Infect 2004; 37 (4): 216 - 218.

15. Ferreira CT, Pereira Lima J, Barros FC. Soroepidemiologia da hepatite A em dois grupos populacionais economicamente distintos de Porto Alegre. GED 1996; 15 (3): 85 - 90.
16. Focaccia R, da Conceição OJ, Sette H Jr, Sabino E, Bassit L, Nitrini DR, et al. Estimated prevalence of viral hepatitis in the general population of the municipality of Sao Paulo, measured by a serologic survey of a stratified, randomized and residencebased population. Braz J Infect Dis 1998 Dec; 2 (6): 269-284.

17. Department of Health and Human Services. CDC - Centers for Disease Control and Prevention. Disponível em: http:// www.cdc.gov/ Accessed: 12/15/2005.

18. MMWR Morb Mortal Wkly Rep. 1999;vol.48:247-252.

19. MINISTÉRIO DA SAÚDE. Secretaria de Vigilância em Saúde. DOENÇAS INFECCIOSAS E PARASITÁRIAS. Hepatite A.GUIA DE BOLSO, $4^{\text {a }}$ edição ampliada, 2004, págs. 168-172.

20. Ciocca et al. Clinical course and consequences of hepatitis A infection. Vaccine. Vol. 18, Sup. 1, Feb. 2000, P S71-S74

21. Debbag et al. 10 Years Experience in Fulminant Hepatic Failure due to Hepatitis A. Costs and Evolution. ICID 2004 Abstract No. 1682.

22. Lopez, E.; Debbag, R. ; Coudeville, F. ; Papillon, J. The costeffectiveness of universal vaccination of children against hepatitis A in Argentina: results of a dynamic health-economic analysis. Journal of Gastroenterology. Vol. 42, N. 2 / Feb., 2007.

23. Valenzuela MT, Jacobs RJ, Arteaga O, Navarrete MS, Meyerhoff AS, Innis BL. Cost-effectiveness of universal childhood hepatitis A vaccination in Chile. Vaccine 2005 Jul; 23 (32): 4110-9.

24. Jacobs RJ, Greenberg DP, Koff RS, Saab S, Meyerhoff AS. Regional variation in the cost effectiveness of childhood hepatitis A immunization. Pediatr Infect Dis J., 2003 Oct; 22(10): 904 14.

25. Deneke MG, Arguedas MR. Hepatitis A and considerations regarding the cost-effectiveness of vaccination programs. Expert Rev Vaccines 2003 Oct; 2 (5): 661-72.

26. Dagan R, Leventhal A, Anis E, et al. Incidence of hepatitis A in Israel following universal immunization of toddlers. JAMA, 294:202-210; 2005

27. Rosenthal P. Cost-effectiveness of hepatitis A vaccination in children, adolescents, and adults. Hepatology, 2003 Jan; 37 (1): $44-51$.

28. Wasley A, Samandari T, Bell BP. Incidence of hepatitis A in the United States in the era of vaccination. JAMA, 294:194-201; 2005. 